\title{
Respecting human rights is the sine qua non for all mental health care and support: the strategy of MindFreedom International
} David Oaks

\author{
Address: MindFreedom International, POB 11284; 454 Willamette, Suite 216, Eugene, Oregon 97440-3484, USA \\ from WPA Thematic Conference. Coercive Treatment in Psychiatry: A Comprehensive Review \\ Dresden, Germany. 6-8 June 2007 \\ Published: 19 December 2007 \\ BMC Psychiatry 2007, 7(Suppl I):S89 doi:10.1 I86/I47I-244X-7-SI-S89
}

This abstract is available from: http://www.biomedcentral.com/I47I-244X/7/SI/S89

(C) 2007 Oaks; licensee BioMed Central Ltd.

The World Health Organization (WHO) declared there is a "global emergency" of human rights violations in the mental health system. We look at this emergency from the point of view of individuals who identify as survivors of rights violations while in mental health care.

We focus on three types of coercive human rights violations: 1) Force with intrusive, irreversible procedures. We use two examples: (a) Involuntary electroconvulsive therapy (ECT) against the expressed wishes of the subject is a documented practice in both developed and developing nations. WHO has stated an intent to ban what is commonly known as "forced electroshock" absolutely and internationally. (b) Long-term, high-dosage administration of neuroleptic psychiatric drugs on an outpatient basis, using court orders, is now a fairly common practice in the USA and several other countries. Increased use of "involuntary outpatient commitments" or "community treatment orders" are opposed by every known client organization, but is favored by many professional organizations. We examine this controversy by focusing on the implications of recent medical evidence (brain scans, autopsies, animal studies) that long-term use of high-dosage neuroleptics is linked to structural change in the higher level areas of the brain.2) Fraud. All agree full informed consent is important, but what if physicians themselves are not informed of significant hazards that psychiatric drug manufacturers may be aware of? 3) Fear. If a family with a member in severe crisis is primarily or only offered psychiatric drugs, when non-drug approaches can work, this too is a kind of coercion. Decades ago coerced psychiatry was most common in back wards. Today with globalization and marketing of psychiatric care to the general population, the "fear of no alternative" is one of the most common forms of psychiatric coercion. Creating more non-drug voluntary alternatives is a fundamental human right. 